\title{
MARgINAIS DE SEGUNDA CLASSE: VIAJANDO PELO VELHO CHICO
}

\author{
Raimundo Carvalho* \\ UFES \\ raycarvalho@uol.com.br
}

RESUMO: Leitura do livro de poemas Segunda classe, de Cacaso e Luís Olavo Fontes, destacando suas qualidades de livro de viagem, a partir das categorias de testemunho, do humor e do paradoxo. Os poemas de ambos os poetas captam com perplexidade a existência de elementos da modernidade imbricados na realidade arcaica do sertanejo, criando uma sensação de nonsense e desconforto que oscila entre a apatia e a dor na percepção do nosso atraso social.

Palavras-chave: Poética. Viagem. Humor.

ABSTRACT: I propose a reading of the book of poems Second Class, by Cacaso and Luis Olavo Fontes, highlighting its qualities as a travel book, through the categories of testimony, humor and paradox. The poems of both poets capture with perplexity the existence of elements of modernity intertwined in archaic reality of the backcountry, creating a feeling of nonsense and discomfort that oscillates between apathy and pain in the perception of our social backwardness.

Keywords: Poetics. Travel. Humor.

* Professor do Programa de Pós-Graduação em Letras (PPGL) da Universidade Federal do Espírito Santo (UFES).

Revista Texto Poético I ISSN: 1808-5385 | Vol. 20 (1o sem-2016) - p. 208 
O foco deste texto é traçar um breve enquadramento do livro Segunda classe, de Cacaso e Luís Olavo Fontes. A obra circulou em 1975, em livreto, à moda marginal, como era de praxe na época. O rótulo marginal fica por conta de sua restrita circulação. Os ditos poetas marginais na verdade eram jovens da classe média urbana intelectualizada. A maioria era composta de estudantes, professores universitários ou até mesmo de diplomatas. Nada mais distante, portanto, do que era ou viria a ser a verdadeira marginalidade social ou a barra pesada do crime. O tipo de poesia que se praticava nesses grupelhos reunidos em torno de alguns nomes e revistas se opunha, programaticamente, a um gênero de poesia grandiloquente e de fácil aceitação pelas editoras e pelo público, como se opunha também ao cerebralismo da poesia concreta e das demais vanguardas da poesia visual. Muito já se escreveu sobre isso, mas é sempre bom relembrar, a poesia que se convencionou chamar de marginal nada tem de marginal no sentido corrente que essa palavra tem no contexto social brasileiro. Ela não se pretende porta-voz de nenhum grupo excluído. Muito ao contrário, ela denuncia energicamente a falácia das filiações políticas explícitas da mensagem poética e o conservadorismo estético dessa posição de combate aparente.

Essa breve colocação já nos dá a dimensão da dificuldade que teremos em nossa leitura da obra. Como perceber nela certas constantes do pensamento e da atitude do intelectual brasileiro na percepção de nossa complexa realidade cultural e social? Como perceber, nessa poesia tão infensa à palavra de ordem e ao engajamento político explícito do texto, questões que sempre preocuparam e continuam ainda a preocupar as mentes que se aplicam a entender o que verdadeiramente se passa no Brasil? 
Nesse sentido, começo filiando esse livro a uma larga corrente de textos de autores e gêneros diversos, viajantes brasileiros que esquadrinharam o território à procura, talvez, de nossa identidade dilacerada, em meio à diversidade étnica e aos desequilíbrios sociais. Dentro desse grupo de viajantes, particularizo aqueles que, seguindo a rota traçada por Teodoro Sampaio e Euclides da Cunha, percorreram o São Francisco, principalmente o seu curso médio, onde vicejou durante décadas no século XX uma intensa navegação de Vapores, nos moldes daqueles que existiram no Mississipi. Das corredeiras de Pirapora (MG) a Juazeiro (BA) e Petrolina (PE) são cerca de 1.321 km de trecho navegável e, por ele, passaram poetas, romancistas, jornalistas e políticos que deixaram seus relatos em forma de diários, romances, poemas, estudos e reportagens. Muitos desses intelectuais, instruídos na divisão litoral/sertão, viam no São Francisco e em suas populações uma espécie de cena primitiva, de lugar de origem, no sentido de que, afastado do bulício da civilização que grassou no litoral, o cerne do território, banhado pelas águas do Velho Chico, teria conservado a essência de nossa brasilidade.

Daí a ideia do rio como fator de unidade nacional, chave para a conservação do vasto território brasileiro. Desde muito cedo, o rio teria atraído a atenção do colonizador e foi usado por este como rota de interiorização. O rio serviu também como caminho natural de encontro entre a civilização do couro e a civilização do ouro, uma alimentando a outra de víveres e servindo como rota de escoamento de bens e acumulação de riquezas. Os sertões, de Euclides da Cunha, sintetiza toda uma tradição de relatos, e Grande sertão: veredas, de Guimarães Rosa, completa em chave ficcional o mapa do sertão sanfranciscano. Autores como Lúcio Cardoso (Maleita), Jorge Amado (Seara Vermelha), Raquel de Queirós (Dora Doralina) trazem relatos 
ficcionais da mesma viagem empreendida pelos nossos dois poetas, na década de 70 .

O rio - que no período colonial servira de rota de integração e que na primeira metade do século $\mathrm{XX}$ foi rota de fuga dos retirantes nordestinos para São Paulo - transformou-se nas décadas de 60 e 70 em trilha de desbunde e turismo interno de hordas de jovens da classe média urbana, que, por terra, através dos trens, chegavam à Pirapora, em férias, para pegar a barca, numa viagem que se tornou, durante um período, uma espécie de batismo, rito de iniciação: viajar pelo São Francisco, conhecer as populações ribeirinhas, animados pelas reportagens das revistas Cruzeiro e Realidade; ou simplesmente andar a esmo, testando as inúmeras rotas existentes então $0^{28}$.

Estávamos em pleno período ditatorial. Nada melhor que simular certa inocência e assim driblar os poderes muitas vezes implacáveis, mas que, em geral, já mostravam certo cansaço e até mesmo tolerância com as diabruras dos filhos da classe média. Lembro-me, perfeitamente, como morador da cidade de Pirapora que, íamos, curiosos, receber aqueles "cabeludos" que chegavam aos bandos e ocupavam durante dias, antes de embarcarem, as pensões baratas. $\mathrm{O}$ padre acolhia no Salão Paroquial, com indulgente hospitalidade, muitos daqueles que queriam economizar alguns trocados com hospedagem gratuita, pois a viagem estava só começando. Nós, os meninos e jovens do lugar, ficávamos por ali a espreitar os hábitos

${ }^{28}$ Sobre Segunda classe, afirma Messeder: "Este trabalho é o resultado da viagem que os dois autores realizaram juntos, no 'vapor do São Francisco', de Pirapora a Juazeiro. Essa mesma viagem, por sua vez, tinha naquele momento - e, de certa forma, ainda tem hoje um significado todo especial. Era uma experiência obrigatória no universo do 'desbunde'. O contato intenso com a natureza, a caminhada pelo interior, a 'lentidão' do tempo e principalmente o contato com as populações locais eram experiências valorizadas. E é esse universo que o livro busca expressar" (PEREIRA, 1981, p. 295).

Revista Texto Poético | ISSN: 1808-5385 | Vol. 20 (1o sem-2016) - p. 211 
lisérgicos e a liberdade sexual dos visitantes até que eles partissem no Vapor deixando saudade.

Era década de 70; portanto, estávamos distantes do sentimento de exaltação da brasilidade destilado no poema "O rio de São Francisco", de Jorge de Lima, fruto de suas leituras de viajantes estrangeiros e de uma viagem empreendida pelo poeta, ainda nos anos 10, mas, em contrapartida, muito mais próximos da sensação de agonia pela morte do rio descrita no poema "Águas e mágoas do rio São Francisco", de Carlos Drummond de Andrade, algumas vezes referido no livro dos dois marginais. Esses dois poemas poderiam figurar como marcos que sinalizam um percurso pendular que vai da exaltação encomiástica de nossas farturas à exposição honesta de nossas fraturas internas. Não custa lembrar que o genuíno sentimento de pertencimento à Terra Brasilis foi manipulado pelos artífices do Golpe e transformado no patriotismo fratricida do "ame-o ou deixe-o", numa operação simbiótica que fazia coincidir o poder ditatorial com o sentimento de brasilidade. No baixo repertório do cancioneiro brega, a canção "Eu te amo, meu Brasil", de Dom e Ravel, ilustra bem essa diretriz.

Passemos então a uma breve descrição do livro Segunda classe. Trata-se de uma série de 50 poemas (24 de Cacaso, 26 de Olavo Fontes). A edição que utilizo se vale de um artifício tipográfico para indicar a autoria de cada poema, alertando, no entanto, que na edição dos autores, prevalecia a indistinção, artifício que aponta para a maneira como seus autores percebiam o jogo literário. Trata-se mesmo de um livro a quatro mãos de poemas que apresentam uma estrutura serial e dialógica na própria fatura. Os poemas, como de praxe, são curtos, à exceção de um intitulado "Januária", cujo tamanho supera os demais. O caráter serial, programado e construído do livro é evidente. Os poemas funcionam como um conjunto, ainda que o seu modo de 
composição crie um efeito de instantaneidade, portanto, de quebra. $\mathrm{Na}$ sua fatura técnica essa série de poemas se filia à vertente pau-brasil, é uma atualização do modus operandi oswaldiano ${ }^{29}$. A epígrafe do livro é de Oswald de Andrade. Vem de Oswald o humor telegráfico dos poemas marginais, humor como operação estética refinada na percepção de nosso atraso social.

Antes de falarmos do título, a capa e a foto ou fotomontagem da capa merecem algumas considerações. A imagem lembra um fotograma ou mesmo o cartaz de um filme do Cinema Novo. No primeiro plano, ocupando o centro, um toco calcinado e torto sustenta uma cerca de arames quase invisíveis, dividindo o espaço da capa em dois. Num plano mais recuado, dois magros bois, um mais à frente em posição frontal apontando os seus chifres para o leitor e outro ao fundo, de perfil, do lado esquerdo; do direito, vemos bem na extremidade inferior da capa um perfil de galinha, bico voltado para o centro da cena. Uma superfície esturricada é a base da paisagem. $\mathrm{O}$ todo da composição dá-se em cortes, planos e montagens, em fotogramassíntese dos elementos que juntos representam ao mesmo tempo uma paisagem geográfica e uma construção mental. O título e o nome dos poetas estão em minúsculas, compostos em futura, tipo amplamente utilizado pelos concretistas em suas edições de poesia.

Nessa paisagem, a figura humana não está, digamos, figurada. Mas todos os elementos indiciam a presença do homem: a cerca, os animais domésticos que fazem parte da dieta humana. $\mathrm{O}$ homem é o fotógrafo que do rio flagra as margens. O rio é o mais além da

${ }^{29}$ COSTA LIMA (1991, p.195), estudando a poesia de Oswald, afirma: “Ao passo que o poema é autônomo, como decorrência de sua estrutura interna, a série supõe que a sua unidade é alcançada por uma sequência de textos, sendo pois dotada de uma estrutura próxima da novela curta e do romance".

Revista Texto Poético I ISSN: 1808-5385 | Vol. 20 (1o sem-2016) - p. 213 
paisagem, o além da capa. Quando viajamos, vemos a paisagem como num filme. Parados dentro do Vapor que se move, a paisagem passa por nós como uma película. A cerca em primeiro plano metonimicamente nos reporta ao autoritarismo vigente. Portanto, a iconografia de uma paisagem pitoresca do sertão funciona também como ideograma da cena política, encurralada.

O título Segunda classe pode ser lido em várias chaves. A primeira é como referência direta ao lugar ocupado pelos poetasviajantes no Vapor. O Vapor Venceslau Brás, como a maioria dos gaiolas, tinha dois compartimentos para os viajantes: uma primeira classe, onde se abrigavam os turistas e viajantes que podiam pagar para viajar em camarotes na parte de cima, e uma segunda classe, onde os ribeirinhos simples se acomodavam em redes. Os jovens cabeludos dos anos 60/70, a que nós ribeirinhos chamávamos de hippies, claro, se amontoavam também junto com o povo da região. Aquela mistura fazia parte do rito, criava uma espécie de solidariedade entre desiguais, alimentada ainda por uma esperança sincera e ingênua de apagamento de diferenças culturais e sociais. $O$ barco se transformava num território de consenso e trocas simbólicas entre os grupos. De um lado, a alegre disposição daqueles rapazes e moças com seus hábitos modernos demais; de outro, a inclinação natural do sertanejo para conversa e música. Ali durante seis dias ou mais, a depender da estação e do regime das águas, o Vapor seguia o curso do rio, parando nos portos de lenha e nas principais cidades, onde era aguardado com certa expectativa pelos habitantes. Na década de 70, a navegação do Médio São Francisco, que teve o seu auge nas décadas de 40 e 50, entrou em declínio.

Segunda classe também pode ser lida em chave metalinguística. Como título, a expressão contamina todo o conteúdo estético do livro. 
Segunda classe é uma referência ao processo de esvaziamento da retórica da poesia de conteúdo explicitamente engajado. A retórica inflada do elogio da brasilidade é golpeada a cada poema revelador do seu mecanismo. O sentido pejorativo do termo é assumido ambiguamente pelos poetas como provocação, como desnudamento diante de uma realidade adversa, diante da própria poesia. É como se a poesia sofresse na própria pele das palavras a doença que ela denuncia e acolhe em si. A poesia de segunda classe é magra, descarnada, assim como os seres de segunda classe, os explorados e iludidos pela gorda retórica de seus dominadores.

Antes de adentrarmos os poemas do livro, vale ressaltar o poema de Chacal, em que ele apresenta o tema da viagem e enuncia, ironicamente, o modo de construção do poema típico de sua geração, que se constitui num verdadeiro despiste da operação construtiva efetivamente levada a efeito pelos poetas, tanto na elaboração isolada de cada poema, como na organização do conjunto ${ }^{30}$. O texto seguinte, de Augusto Ribas Lopes, funciona mais como uma contextualização do tema propriamente dito, através das referências aos nomes das cidades que extremam o Médio São Francisco, ao nome da barca em que os poetas viajaram, além de anotar a presença fantasmática das obras de Guimarães Rosa e Oswald de Andrade. A epígrafe oswaldiana, "Que a poesia é a descoberta/ Das coisas que eu nunca vi", fecha o círculo dos paratextos ${ }^{31}$ e se projeta para dentro do livro, como

${ }^{30}$ Esse tipo de despiste era norma. O próprio Cacaso, em depoimento, diz que Segunda classe "é uma coisa informal (...) inclusive eu não tenho a menor pretensão de ler aquilo como poesia, é um negócio (...) meio repentista assim (...) A gente estava nessa curtindo, a verdade é essa (...) o acontecimento em si mesmo já estava bom, independentemente do resultado literário" (PEREIRA, 1981, p. 296).

${ }^{31}$ Além desses paratextos, reproduzidos na edição consultada, há outros constantes da edição dos autores, citados por Messeder: “Após a indicação dos nomes que compõem a

Revista Texto Poético | ISSN: 1808-5385 | Vol. 20 (1o sem-2016) - p. 215 
uma espécie de moldura. Portanto, podemos perceber, desde o início, uma intenção construtiva envolvendo todas as etapas de produção do livro como um objeto orgânico, cujas partes se comunicam e produzem um sentido de totalidade. Esse sentido de totalidade virá da soma e do diálogo entre os poemas, eles próprios fragmentos de cenas e flashes de acontecimentos sempre captados através da proposição do nonsense e do paradoxo.

Os versos do primeiro poema ("Os vermes devoram a galinha. $\mathrm{O}$ rio/ devora os vermes e se devora./ É logo ali Pirapora”) funcionam como uma desmontagem do título "Município". O que parecia dar início a uma descrição cartorial desloca-se. O foco desvia-se para os vermes. $O$ banquete se faz em chave agônica, do microscópico ao macrocosmo. A visão do território se envenena, a presença humana apenas se insinua na figura da galinha e na frase que finaliza o quadro que parece reproduzir a voz do nativo indicando o caminho. $\mathrm{O}$ rio e os vermes se equiparam no ato de devoração. Tudo isso lembraria mais uma observação de sanitaristas em expedição pelo Vale, não fossem os artifícios poéticos do texto: a repetição de vocábulos, a disposição das orações nos versos e as recorrências sonoras de sílabas e palavras. Sem rodeios o poeta apresenta de cara esse sentimento de impotência e desacordo face às nossas mazelas sociais. $\mathrm{O}$ território, que na retórica da voz senhorial se reveste de tantas riquezas e símbolos, é aqui apresentado ao avesso, como o negativo da fotografia oficial. O poema seguinte, "Silêncio", responde ao de Cacaso, seja na extensão da imagem da devoração dos elementos, seja na descrição de uma paisagem desolada. Os 12 poemas que vão de "Utopia" a "Óbvio" são anotações de cenas e pensamentos registrados no período de espera da

'ficha técnica' os autores afirmam: 'A todos esses competentes artistas/desejamos os reinos da/terra"" (idem).

Revista Texto Poético | ISSN: 1808-5385 | Vol. 20 (1o sem-2016) - p. 216 
partida do barco. Comecemos com "Utopia": "nas margens do São Francisco quero/sentar para namorar".

Aqui o mesmo artifício de quebra de expectativa entre o título e o corpo do poema. Utopia, em suspenso no título, descreve uma mudança de concepção e enfoque. Em vez de construir um discurso utópico para apaziguar a consciência culpada pela miséria entrevista, o poeta prefere uma singela celebração erótica, bem mais à mão. $\mathrm{O}$ poema seguinte completa a cena. A "dona do cantil" é com certeza uma daquelas muitas moças modernas que vieram no mesmo bando de forasteiros e cabeludos. A repetição dos verbos sumir/aparecer, atribuídos à dona e ao cantil, sugere maliciosamente o movimento de amantes eventuais em meio à turba. Enfim, a paisagem está corroída, mas o idílio é possível. As cenas de idílio amoroso se mesclam ao pitoresco do lugar. Os forasteiros encontram na cidade interiorana a acolhida necessária para a criação de uma identidade transitória feita de afetos transitórios. O correio, a papelaria, as bicicletas, o circo, os bares perfazem o espaço urbano incrustado na paisagem cultural do sertão, e são notados não em si mesmos, mas em função desse uso transitório. O humor é arma constante de Cacaso, e os poemas de Fontes alternam uma postura mais séria com quedas ocasionais no jocoso. É dele o dístico "Óbvio" que encerra a sequência: "A melhor Coca-Cola de Pirapora/ é a do bar Califórnia". O poema fora do conjunto seria um poema-piada a mais. Mas, lido na série, ganha significação maior, adquire certa narratividade, além de funcionar como um emblema de encontros interculturais insólitos. As cidades sertanejas são lugares de sínteses de elementos heteróclitos. O "Bar Califórnia" é o ícone caboclo do sonho de liberdade da juventude urbana e moderna, e a Coca-Cola se descola do poema concreto, volta a descer sem culpa a goela da rapaziada sob o sol do sertão. A 
obviedade do título se dá inteiramente na linguagem, no truísmo da frase. $\mathrm{O}$ insólito se inscreve no nome indígena da cidade interposto entre os nomes "americanos" da bebida e do bar, aliás, bar predileto da moçada forasteira à época.

Enfim, é hora de pegar o Vapor e partir. Em "Lenços brancos", Luís Olavo Fontes anota os "fagotes alucinados", referência explícita aos proverbiais apitos do Vapor antes e durante a partida, misturados ao som das aves e, quem sabe, percebidos de maneira alucinada pela mente alterada do poeta. Essa sensação auditiva continua no poema seguinte, "Ave", dando a ideia de prolongamento da viagem. O poema de Cacaso, "São Francisco", aqui nome de cidade e não do rio, é próxima parada do barco e uma quebra no tom lírico dos dois poemas anteriores: "O velhinho saiu da janela pra não ser/ fotografado./ Coisas de criança". O humor de Cacaso dá-se em paradoxos e inversões. É sofisticado porque a graça dele dá-se no desvio, na quebra da expectativa. A sutileza aqui fica por conta da negativa do velhinho em aceitar fazer parte do enquadramento do fotógrafo e na atribuição de ingenuidade ("coisas de criança", diria o fotógrafo) à atitude contestatória à invasão de privacidade.

É importante lembrar que as vozes registradas nos poemas nem sempre coincidem com a voz do poeta. Portanto, para entendê-los é necessária certa malícia interpretativa. Vejamos, entre outros exemplos, o poema "Moda de viola": "Os olhos daquela ingrata às vezes/ me castigam às vezes me consolam./ Mas sua boca nunca me beija". O título se refere a um gênero de canção apreciado in loco, as modinhas. Os dois primeiros versos se enquadram no recato do gênero, mas o terceiro se constitui numa inovação. "Os olhos", metáfora de um amor puro e desinteressado, são substituídos pela "boca" da amada, na lúbrica queixa do poeta. Para além do quadro delineado, o poema, 
como os demais, precisa ser compreendido no contexto da viagem. A viagem no Vapor representava um momento de suspensão de uma determinada ordem. Viajando no rio, dentro de um clima de cordialidade entre tripulantes e turistas, a ordem era relaxada. $\mathrm{O}$ comandante tendia a exercer a sua autoridade de forma magnânima diante dos pequenos abusos e dos hábitos sexuais e lisérgicos dos jovens da capital.

Mas nem só de desbunde e orgias viviam os nossos poetas. Ao lado desse espírito zombeteiro, há também a perplexidade e a dor. $\mathrm{O}$ desconforto diante de uma realidade ali descortinada, contaminando a paisagem. O poema "Januária nas janelas", de Luís Olavo Fontes, merece uma parada. É o poema mais longo da série e é ele mesmo um poema em três movimentos. O título faz referência a uma canção de Chico Buarque, e poderia ser tomada como uma espécie de trilha sonora do filme que vem a seguir: "Januária/ uma praça/ onde se vende cachaça" é uma tomada panorâmica que apresenta o cenário do filme. "Vida secas/ um soldado amarelo pisando/ o pé de Fabiano/ pitam os farrapos de Sinhá Vitória/ várias Baleias mortas". A montagem/citação é explícita. O poeta superpõe ao que vê os fotogramas do filme de Nelson Pereira dos Santos e as imagens de Graciliano Ramos. A visão das mangas maduras ameniza o miserê, mas um cachorro preto impede o acesso ao paraíso do quintal (Diz o poeta em outro poema: "quem foi que disse que Paraíso não existe?/ Existe sim, mas tem cascavel”). "A negrinha", Eva nativa, negocia o afeto com o turista. No segmento II, sucedem flashes expressionistas, as imagens fluem em ligeiras ecfrases objetivas e sensações subjetivas: "restos/ favelas/ apodrecendo/ exaustas/ as criancinhas pediam fotografias/ mãos vazias/ procurei em vão no céu sem pipas". O segmento III parece encenar o apaziguamento: "Seis horas fez um cartão postal no/ São 
Francisco// deixei Januária no silêncio crepúsculo das/ mortes vermelhas/ comendo uma manga/ espada/ céu e manga sangrando os beiços/ uma só cor/ esbagaçada// Januária é nome bonito". Aqui se observa uma fusão sinestésica entre as cores do pôr do sol, da fruta e o sentimento de desconforto diante da dor alheia. O escape se dá na linguagem, na pura performance onomástica. $\mathrm{O}$ poema seguinte, "Januária", de Cacaso, resume em seu nonsense as delirantes imagens do poema de Fontes: "A doida vagava na rua não ia a/ lugar nenhum/ Já tinha chegado". Um outro poema de Cacaso, não incluído na primeira edição de Segunda classe, "Tarde em Januária", apresenta uma variação da imagem manga/cão do poema de Fontes: "mangas rosas vermelhas e o negro/ cão mangas rosas vermelhas verdes/ e o negro cão mangas rosas vermelhas verdes/ e o negro cão". O poema excluído atesta o caráter construtivo do livro, que ultrapassa a mera recolha de poemas feitos ao calor da viagem.

Assim, a viagem se constrói como aventura poética e existencial. $\mathrm{O}$ barco avança e adentra o território da Bahia. O rio também muda, fica mais caudaloso. Suas águas mudam de cor, de barrentas tornamse negras. Em "Berço Esplêndido", de Cacaso, a única nota de humor existente é o título que se apropria da expressão do hino nacional: "De águas pretas e mansas é feito meu sangue/ onde toda fúria é represada. Nada compensa a/ lentidão da miséria jamais na lembrança/ sepultada/ Imperceptível meu braço fende - como num coice -/ o crânio rubro da madrugada." Aqui o tom em nada lembra as breves anotações de caráter erótico/jocoso de muitos poemas do livro, em que Cacaso parece se entreter durante a viagem. Aqui ele se aproxima da técnica interseccionista mais utilizada por Fontes, em que se mesclam observações objetivas a respeito da paisagem e sensações subjetivas de espanto ou desamparo. O poema é uma espécie de Noturno. O 
vocábulo "berço" do título já enquadra o poema no gênero. No primeiro período do texto fica claro que o sujeito da enunciação é o próprio rio, humanizado pelas metáforas do sangue e da fúria, fúria represada, metonimicamente disposta no texto, como em trecho do rio (o lago de Sobradinho). No segundo período, o poeta-rio se angustia com a condição humana dilacerada pela miséria que vê e que o marcará para sempre. No último segmento, a imagem do "braço" remete tanto ao "braço do rio" como ao gesto retórico, imperceptível, do poeta. A imagem final, "O crânio rubro da madrugada", além de evocar o colorido intenso do arrebol matutino, visto de dentro do Vapor, evidencia a fusão entre o homem (poeta) e a natureza (rio). O gesto esboçado é abrupto e instintivo (coice). Cacaso enfim consegue o milagre poético de fazer um poema contendo as palavras sangue, fúria, miséria, madrugada, sem incorrer nos lugares-comuns da poesia dita engajada, que ele tanto criticou e combateu. Não há aqui nenhuma glorificação do povo, nenhum incitamento explicito à revolta, nenhuma promessa no amanhã. Mas também não há conformismo, daí o humor nuançado do título. As rimas represada/sepultada/madrugada demarcam os perigos e os limites retóricos do poema, que são driblados pelo poeta através do gesto de escandir (fender) os versos em sucessivos enjambements e mudar-lhes o andamento previsível.

A viagem de Vapor termina em "Petrolina condenada" e no "Juazeiro devasso", e os nossos poetas rumam para Salvador. Com o humor metalinguístico de "Corpo a Corpo", de Cacaso, encerro esta minha viagem particular pelo Velho Chico, tendo como guia o olhar viajante (no sentido rotineiro e lisérgico do termo) dos dois marginais: "estava dançando bem até que a Bahia/ passou uma rasteira no meu verso".

E para terminar mesmo, cito outro poema de Cacaso, descartado e sem título, um convite/provocação ao desbunde: "Quem ainda não 
comeu banana/ na beira do São Francisco não sabe o que/ está perdendo/ Comer banana-maçã na beira do São/ Francisco. Vivendo e aprendendo". É. Estávamos nos anos 70. O São Francisco, assoreado e poluído, perdeu muito de sua navegabilidade. Aquele mundo dinâmico, intenso e cheio de vida e movimento, flagrado pelas lentes de Marcel Gautherot e de tantos outros fotógrafos, resiste como teimosia e memória. Há muito que se deixou de pensar o Brasil como nação soberana, para percebê-lo como campo de experimentação do capitalismo internacional. Os poemas de Segunda classe, no seu aparente descompromisso, dão-nos o testemunho da tragédia que se abateu sobre o rio e o povo das margens e também revela o compromisso ético daquela geração de poetas.

\section{Referências}

CACASO. Lero lero. Rio de Janeiro: 7 Letras; São Paulo; Cosac\&Naify, 2002.

COSTA LIMA, Luiz. Pensando nos trópicos. Rio de Janeiro: Rocco, 1991. PEREIRA, Carlos Alberto Messeder. Retrato de Época: poesia marginal Anos 70. Rio de Janeiro: Funarte, 1981. 